\title{
Regeneration of Digits and Forelimbs in the Kenyan Reed Frog Hyperolius viridiflavus ferniquei ${ }^{1,2}$
}

\author{
CHRISTINA M. RICHARDS, BRUCE M. CARLSON AND \\ SHERRY L. ROGERS \\ Departments of Zoology and Anatomy, University of Michigan, Ann \\ Arbor, Michigan 48104
}

\begin{abstract}
Newly metamorphosed individuals of the Kenyan reed frog, Hyperolius viridiflavus ferniquei, are able completely to regenerate amputated digits, including the morphologically complex digital pad. The sequence of morphological events is very similar to that seen in the typical epimorphic regeneration of amphibian extremities. Amputated forearms typically produce hypomorphic spike regenerates. Despite the lack of underlying hand and digital structures, an apical "digital" pad commonly differentiates.
\end{abstract}

Anuran amphibians are normally able to regenerate amputated limbs and tails as larvae, but after metamorphosis their regenerative ability is generally restricted to wound healing or sometimes to a hypomorphic cartilaginous spike (Forsyth, ' 46 ; Dent, '62; Polezhaev, '72; Weis, '72). However, only a limited number of genera, e.g. Xenopus and Hymenochirus in the family Pipidae (Beetschen, '52; Skowron and Komala, '57; Goode, '62, '67; Dent, '62), Bombina and Discoglossus in the family Discoglossidae (Polezhaev, '72; Goode, '67) and Rana in the family Ranidae (Schotté and Harland, '43; Rose, '44; Weis, '72) have been well studied. There has been no systematic attempt to survey the other 13 families of anurans.

The genus Hyperolius in the family $\mathrm{Hy}-$ peroliidae (Liem, '70), consisting of more than a hundred forms (Schiøtz, '67, '71, and in press), is distributed throughout central Africa south of the Sahara and along the eastern seaboard. These frogs are noted for their extreme variation in color pattern, which according to Schiøtz ('71) is "possibly greater than in any other vertebrate animal." These reed frogs have enlarged digital pads which facilitate climbing and sitting on vegetation.

During the course of experiments in which Hyperolius were toe clipped for individual identification, it was noticed that juveniles had the ability to regenerate complete digits, including the elaboration of a digital pad. This paper describes the regenerative process and reports the for- mation of a padded spike after removal of a whole hand.

\section{MATERIALS AND METHODS}

The reed frogs used in these experiments were Hyperolius viridiflavus fermiquei (Schiøtz, '71). The parents were caught at Tigoni, Kenya, and eggs fertilized in the laboratory. The fertilized eggs were transported to the Amphibian Facility at the University of Michigan, where the tadpoles were raised to metamorphosis and juveniles cared for according to procedures described in "Amphibians; Guidelines for the breeding, care and management of laboratory animals" (74). Eighty-nine tadpoles metamorphosed between October 2 and October 20, 1973. Snout-rump length immediately after tail resorption was 15 to $17 \mathrm{~mm}$.

Digits were removed from 0 to 27 days after tail resorption (average 9.5 days; median 11 days). The longest digit (3) on the right hand was removed between the digital pad and the first metatarso-phalangeal joint, a length of $1.5 \mathrm{~mm}$. The animals were maintained at room temperature, which varied between 21 and $23^{\circ} \mathrm{C}$. Regenerates were fixed at daily intervals from 0 to 30 days and at 5 day intervals from 30 to 60 days. Initially only the digit with the regenerating tip was removed for fixation, but due to technical problems in

1 Contribution number 52 from the Amphibian Facility.

2 Supported in part by grants from the Muscular Dystrophy Associations of America and NIH Grant No. 1 PO6 RR 00572 to George W. Nace. 
handling the tiny short term regenerates we more often removed the entire hand.

Removal of the hand for fixation in the digit regeneration series then became the basis of a study of regenerating limb stumps. Hands were removed by cutting between the wrist and elbow on November $12,1973,24$ to 33 days post metamorphosis. Regenerates were fixed every 4 days between days 8 and 20 , every 5 days between days 20 and 70 , on day 80 and on day 90. Hands for short term studies were removed from three frogs on January $11,1974,93-94$ days post metamorphosis. These regenerates were fixed on days 1 , 4 and 7.

All regenerates were fixed in Bouin's, decalcified, sectioned at $7 \mu$ and stained with hematoxylin and eosin.

\section{RESULTS}

\section{General growth data}

Removal of a single digit seemed to have little effect on a frog's ability to maneuver and catch live insects. The 52 experimental animals grew an average of $1.2 \mathrm{~mm}$ in 30 days as compared with another group of Hyperolius, which grew $1.3 \mathrm{~mm}$ in the same time. Frogs in both groups also had one or two toes removed from the hind feet for individual identification.

In contrast, removal of a whole hand had a drastic effect on a frog's ability to catch live insects and hence on its growth rate. Such frogs grew only an average of $0.3 \mathrm{~mm}$ in the two months following hand removal as compared with a $4.5 \mathrm{~mm}$ increase in length during the same time interval in unoperated animals.

\section{Gross description of regeneration}

\section{Digits}

Digital regeneration follows a course typical for amphibians. Epithelium first covers the wound surface; then, by the sixth day, the tip of the limb begins to clear and a blastema begins to form. This elongates until on the 14 th day the blastema is longer than it is wide. About this time pigment cells of the undamaged epithelium start migrating into the epidermis of the blastema. On the 18th day the blastema can be seen enlarging at the distal end into a typical broadened digital pad shape. By the 24th day the regenerating digit has grown to the same length as the adjacent digits but still has not attained its original length. The digit is essentially complete by day 30 , including the elaboration of a new toe pad and growth almost to its original length (fig. 1).

\section{Limbs}

Following removal of a hand, the skin contracts around the cut end and epithelium covers the wound surface. At the end of the second week a rounded blastema is evident. During the third week it elongates into a pointed structure, the long axis of which deviates slightly from that of the limb stump. In succeeding weeks the blastema elongates further into a laterally flattened spike. The end of the spike broadens and forms a simple digital pad in the 7th and 8th weeks (fig. 2). The length of the spike plus digital pad at the end of the eight weeks is $2.5 \mathrm{~mm}$ compared with $6.5 \mathrm{~mm}$ from the amputation point to the tip of the longest digit in the unoperated arm. The pad appears to be functional and frogs which could not

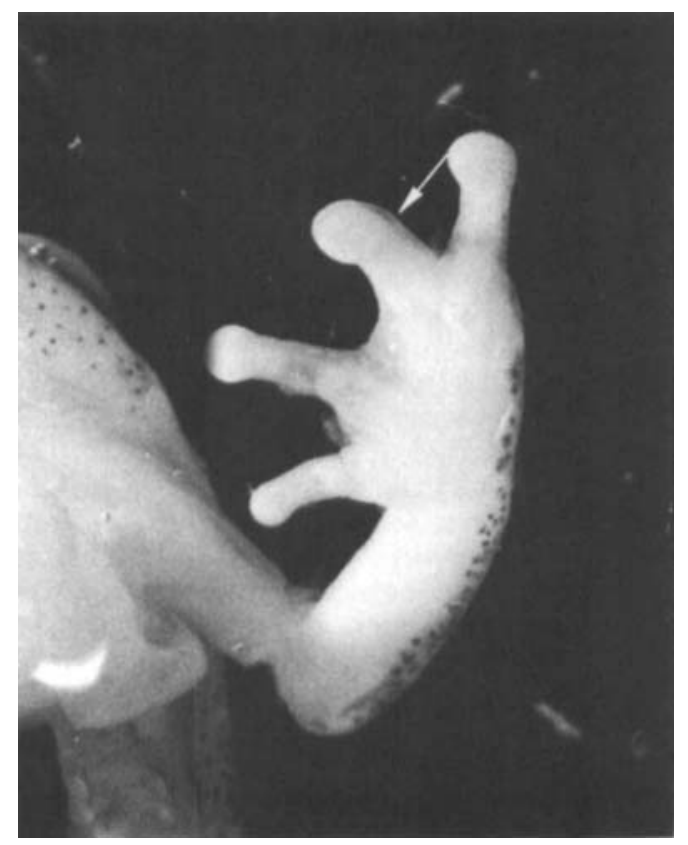

Fig. 1 Gross ventral view of digital regenerate (the third digit) of 60 days. Level of amputation indicated by arrow. The expanded ends of digits represent the digital pads. The regenerated digit is shorter than normal because this is a second regenerate. $\times 8.25$. 


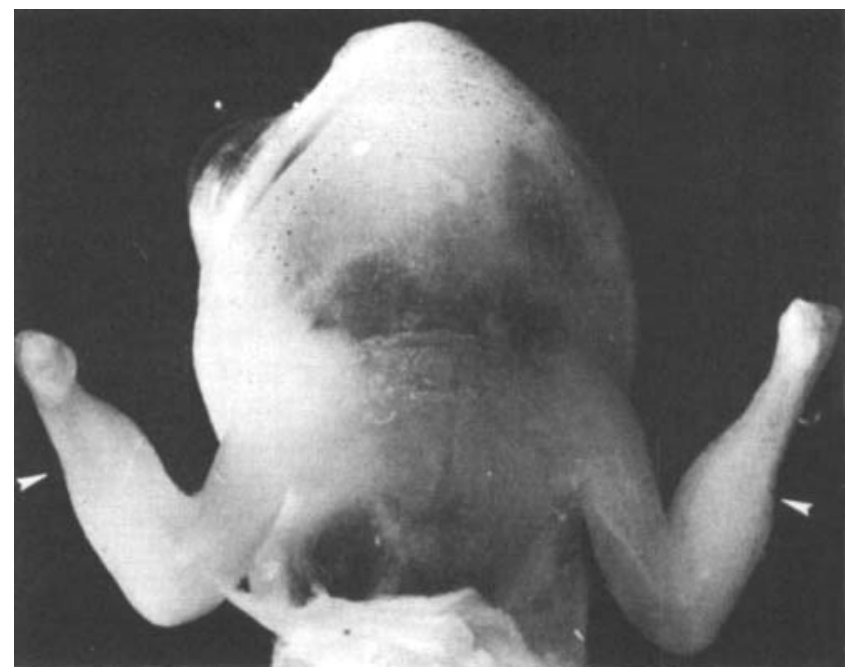

Fig. 2 Bilateral forearm regenerates four months after amputation. Regeneration was essentially complete after two months; no morphological changes took place in the succeeding two months. Level of amputation is indicated by an arrow. The expanded ventral surface of the right forearm regenerate is the new digital pad. The digital pad is not evident on the left regenerate. The surface irregularities are likely due to anomalous carpal elements. No digits are present in either regenerate. $\times 6.75$.

maneuver well enough to capture live food when the arm was first removed now are able to move more readily and capture live food.

\section{Histological description of regeneration} The normal digital pad

After decades of neglect, during which there were only two major reports on digital pad structure (Schuberg, 1895; Noble and Jaeckle, '28), two recent investigations involving modern microscopic techniques have provided a sound morphological basis for studies on anuran digital pads (Ernst, '73a,b; Welsch et al., '74).

The normal digital pad in Hyperolius is a ventral expansion of the skin at the tip of each digit (fig. 3). There are two primary components to the pad: the specialized epidermis and a rich supply of mucous glands buried within the underlying connective tissues (fig. 13). Surrounding the mucous glands is a complex array of bands of densely packed collagenous fibers (Noble and Jaeckle, '28).

The epidermis of the digital pad in Hyla cinerea (Ernst, '73a) is a six layered structure, consisting of a basal germinative layer, three somewhat ill-defined intermediate layers and two outer regular layers of cells. As the cells move from the inner to the outer layers, they produce large numbers of tonofilaments and vesicular structures. In the outer two layers of cells, the tonofilaments are organized into regular dense bundles that cause peg-like projections of the surface plasma membrane. Scanning $E / M$ studies of the surface epithelium of digital pads in Rhacophorus have demonstrated bundles of stout microvillus-like structures projecting from the surface pegs (Welsch et al., '74). The epidermis of the digital pads of $\mathrm{Hy}$ perolius has a histological structure similar to that in Hyla and Rhacophorus, but the number of cell layers is greater, being at least 7-8.

Large numbers of mucous glands are present in the connective tissues beneath the thickened epidermis of the pad. Each gland has a thin, slightly tortuous lumen lined by cuboidal epithelial cells and an expanded secretory portion that is acinar in configuration. There is a well defined lumen within the secretory acinus (fig. 13). Electron microscopic studies have demonstrated a thin myoepithelial or smooth muscle layer surrounding these glands (Ernst, '73b; Welsch et al., '74).

In addition to the epidermal specializations and the mucous glands, Welsch et al. (74) have commented upon a striking 


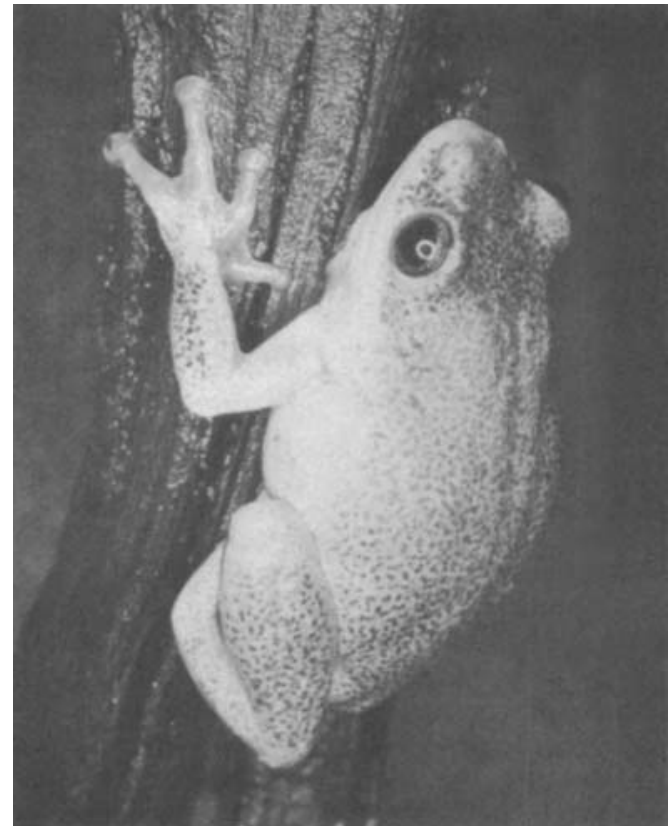

Fig. 3 Lateral view of normal Hyperolius viridiflavus ferniquei demonstrating digital pads on left hand. $\times 2.25$.

abundance of small nerves and nerve terminals within the dermis of the digital pads in Rhacophorus.

\section{Digits}

During the first $24-48$ hours, the amputation surface is sealed off by a wound epidermis 3-4 cells thick in a manner typical of amphibians. Beneath the wound epidermis, areas of directly traumatized soft tissues as well as the end of the transected bone are associated with light accumulations of leukocytic cells and a fibrinous material.

By three days, the cells of the wound epithelium have thickened from their originally squamous shape, but no discrete apical cap has formed. Little evidence of the dedifferentiative reaction is yet seen in the soft tissues of the stump (fig. 4), but the periosteum of the distal 1 or 2 phalangeal segments is beginning to loosen up and the cells are beginning to increase in diameter.

An apical epidermal thickening begins to take shape as early as the fourth postamputational day, and evidence of soft tissue dedifferentiation can now be seen.
Both of these reactions are better defined on the fifth day (fig. 5). At about this time, the skeletal tissues give evidence of a rapid differentiative response to the amputation injury. Cells of the periosteum of the terminal transected phalanx, but even more so, those of the penultimate skeletal segment, continue to swell, and the fibrinous matrix in which they reside becomes thicker and less compact. The reacting periosteum is readily distinguishable from the proximal extensions of the epiphyseal cartilage. These extensions are reminiscent of an overflowing of cells from the cartilaginous epiphysis of the bone (figs. 5, 6).

Toward the end of the first week, osteoclasts begin to attack the transected bone (fig. 6), but their numbers are consistently less than in amputated urodele limbs. By 6-7 days, periosteal cells surrounding the shafts of the last two phalanges are secreting a new cartilaginous matrix (fig. 6). This new cartilage can still be clearly distinguished from that of the epiphyseal "overflow." The dedifferentiation of muscle and other soft tissues is well under way and some of the cells resulting from this reaction appear to have begun to migrate toward the distal part of the limb stump.

Early in the second week the dedifferentiative phase is still predominant, but soon it is succeeded by the formation of a blastema beneath the still thickened apical epidermis. Osteoclasts are still clustered around the distal remains of the skeleton. More proximally in the stump a thick cuff of periosteal cartilage is being formed around the phalanges.

Late in the second week the blastema is fully established and begins to elongate (fig. 7). As this occurs, the configuration of the overlying epidermis changes in a manner very reminiscent of that seen in the regenerating urodele limb. During the late dedifferentiative and early blastemal stages the apical epidermis is noticeably thickened (fig. 6) whereas along the sides it is relatively thin. As the blastema begins to elongate, the apical epidermal thickening diminishes considerably in prominence, and the lateral epidermis thickens (fig. 7). The lateral epidermal thickening is largely due to a pronounced change in the shape of the cells of the basal layer of the epidermis. From a squamous layer during 
the pre-dedifferentiative phases, the basal epidermal cells progressively thicken to become cuboidal as the blastema begins to accumulate (fig. 6). They then continue to increase in height to form a regular layer of columnar cells as the blastema elongates (fig. 7). This phenomenon has been previously noted in the newt (Carlson, '67; Iten and Bryant, '73).

Within the blastema the central core of cells aggregates into a dense rod which soon begins a proximo-distal sequence of deposition of cartilage matrix (fig. 7). Along the shaft of the bone the prominent cuff of periosteal cartilage is considerably further differentiated than the cartilage within the blastema. Muscle is not a prominent component of the terminal part of the digit, but some regenerating muscle fibers are seen deep within the stump midway in the second week after amputation. Occasional muscle fibers do not differentiate within the blastema until several days later.

Starting at the end of the second and early in the third week, the reconstruction of a new digital pad overshadows other differentiative events within the regenerating digit. As early as 14 days, the first traces of apical mucous gland differentiation are seen, and as the third week begins, the ventral epidermis at the apex of the regenerate begins to thicken conspicuously -- this time as a prelude to the differentiation of the specialized digital pad (fig. 8).

Midway in the third week, the thickened epidermis of the regenerating digital pad has begun to develop the obvious layering characteristic of the normal pad (fig. 9). The developing glands are commonly shaped like long-necked flasks. Their cells are still histologically undifferentiated, and mitotic activity is intense (fig. 9).

At the end of the third week the layering pattern of the digital pad is close to normal, and the apical glands have extended deep within the soft tissues of the digital apex (fig. 10). Although each gland can be clearly divided into an acinar and a ductular portion, the cytoplasm of the epithelial cells lining the acini is still incompletely differentiated and gives no evidence of secretory activity.

During the fourth week the tissues of the regenerated digit are well differenti- ated, and their overall organization is much like that of the normal digit. The new skeleton is completely cartilaginous, and it is not uncommon to see remnants of the original bony phalangeal segment deeply embedded within a massive rod of cartilage (fig. 11). By the middle of the fourth week the acinar cells of the apical (mucous) glands appear ready to begin their secretory function.

Regeneration of digits in Hyperolius is almost perfect morphologically. Figure 12 compares a sagittal section through a 30 day regenerate with a similar section through a normal digit (fig. 13). Except for the skeleton, which is still almost entirely cartilaginous, it is not easy to tell at first glance a histological preparation of a 30 day regenerate from a normal digit. As a rule, little muscle is seen in the regenerated portions of the digits. During the second month, the cartilaginous phalanges begin to ossify, starting with an outer bony cylinder. The cytoplasm of the apical glandular cells also undergoes the final steps in its maturation.

\section{Limbs}

The early phases of the regenerative process do not differ substantially from those already described in the digit in this species, or in regenerating limbs of other species. Epidermal healing of the amputation surface is completed within a few days, and during the period of phagocytosis and demolition, there is direct contact between the wound epidermis and the deeper mesodermal tissues. The early reactions of the mesodermal tissues to the trauma of amputation are similar to those which occur in the digit.

Late in the first week and early in the second, both dedifferentiative and tissue healing processes are represented in the distal stump tissues (fig. 14). The wound epidermis maintains broad contact with the underlying tissues, and in the area of contact it is thickened. Already the cells of the basal layer of epithelium are high cuboidal and are regularly arranged. Osteoclasts have eroded much of the distal skeletal matrix. Great masses of periosteal cartilage have already differentiated by 9 days, and this is frequently the dominant tissue component of the stump. Some indication of the extent and rapidity of for- 
mation of the mass of cartilage surrounding the bone is illustrated in figure 15 . This section was taken from the same limb as that illustrated in figure 14, and it shows several skeletal muscle fibers that have become imprisoned within the newly formed cartilage. The portions of the muscle fibers surrounded by cartilage are severely necrotized whereas the more proximal regions of the same muscle fibers are histologically normal.

Two major histological reactions are seen in the stump musculature at this stage. One is the dedifferentiative reaction that is characteristic of regenerating limbs (Thornton, '38; Hay, '68), and in areas of dedifferentiation numerous cells that resemble those found in the blastema are seen. Degenerating nuclei are not uncommon in this area. In other regions of the stump, among apparently healthy muscle fibers are other muscle fibers that are undergoing extensive sarcolysis of the type seen in tissue regenerative processes of frog and mammalian muscle (Carlson, '68, '70).

The most distal parts of the limb stump are occupied primarily by mononuclear cells (fig. 14). In many areas these cells are spindle-shaped and are regularly oriented. Their histological appearance is like that of the precursors of the fibrocellular scar that has often been described in non-regenerating anuran limbs (Schotté and Harland, '43; Thornton, '56). Beneath the naked wound epidermis the mononuclear cells are not so spindleshaped, and they are less regularly oriented than those described above. Except for the thickened wound epidermis in close contact with the underlying tissues, the overall histological appearance of limbs early during the second week after amputation is reminiscent of that of a non-regenerating limb exhibiting the fast tissue healing responses and exuberant proliferation of cartilage around the amputated bone.

By the end of the second week and early in the third, most amputated limbs have developed unmistakable blastemas of varying degrees of prominence (fig. 16). In most blastemas the interior architecture is not so regular and homogeneous as it is in the urodelean blastema, but the homology is unmistakable. The prominent cartilaginous cap surrounding the amputated bone stands in sharp contrast to the undifferentiated appearance of the blastema itself. The basal layer of epidermis covering the blastema is composed of highly regular columnar cells, as was the case in the digital blastemas.

As the blastema elongates during the third week, the central cells condense and begin to differentiate into cartilage. Distally the level of differentiation is less. The blastema is richly vascularized, particularly at the apex. An apical epidermal thickening is still present.

During the next few weeks the limb blastema elongates considerably, but morphogenesis is not carried to completion. Most regenerates are spike-like and contain massive rods of cartilage, sometimes possessing simple joints (fig. 17). Commonly, irregular strips or bundles of skeletal muscle fibers extend varying distances into the regenerates. Their organization appears unrelated to any normal pattern of muscles in the forelimb.

Although the terminal points of the mature regenerates are typically simple with little or no evidence of carpal or digital structures, all possess terminal epidermal specializations and glands of the type seen at the ends of the digits (figs. $18,19)$.

\section{DISCUSSION}

The morphology of a regenerated digit in Hyperolius is virtually the same as that of a normal digit. The major difference is in the skeleton, which typically remains cartilaginous for extended periods of time in anuran regenerates. In addition to normal morphology, the regenerated digits appear capable of normal function on the basis of gross observations.

Although not well documented in the literature, it is known among ecologists that the clipping of digits is not a good way to mark tree frogs because of their tendency to regenerate. In contrast, the regenerative capacity of digits in the closely related ranid frogs is not great. Because of the lack of accurate anatomical information as well as insufficient documentation of digital regenerative ability for most species, it is unwise to propose any concrete hypothesis at this point. A likely pos- 
sibility, however, is that in frogs with expanded digital pads the number of nerves or amount of axoplasm per cross-sectional area of the digit exceeds the threshold value required for regeneration (Singer et al., '67). Particularly in the light of the recent report of Welsch et al. (74), who found large numbers of nerves in the dermis of the digital pads of Rhacophorus, this remains a promising avenue for further exploration.

In contrast to the digits, the incomplete regeneration of amputated forearms in Hyperolius is typical of that found in other frogs possessing some degree of natural regenerative ability. Several investigators have noted the formation of hypomorphic spikes in Xenopus laevis (Komala, '57; Skowron and Komala, '57; Dent, '62; Overton, '63), and similar structures have regenerated after limb amputation in Bombina (Polezhaev, '72; Goode, '67), Hymenochirus (Goode, '62), Discoglossus (Goode, '67) and Xenopus mülleri (Goode, '67).

Limb regeneration in Hyperolius is dominated by a central core of cartilage, occasionally possessing one or two distal joints. Although rarely a few small cartilaginous masses have been found distally, these masses cannot be assigned to any specific bones of the carpus or manus. In none of our regenerates could it be said that digit formation took place. Surrounding the cartilaginous core, the regenerated connective tissues and muscle bundles are also morphologically deficient in both quality and amount. The most peculiar feature of the limb regenerates is the formation of rudimentary, but clearly recognizable digital pads at the ends of all mature spikes.

The complete regeneration of the digital pad after amputation through the digital level and the appearance of a simple pad at the end of hypomorphic forelimb regenerates suggest the selective advantage of restoring this structure after its loss or damage. This interpretation is strengthened by the observation that animals with a hand removed were unable to capture enough live food to support growth. In captivity, these frogs perch vertically on the sides of the containers, leaving this position primarily to feed. Of particular interest is the formation of digital pads on the regenerated limb spikes. The pad (thickened epidermis and associated mucous glands) is the most distal epidermal structure on the limb, and yet it forms over a regenerate which, according to its skeletal and muscular structure, has not regenerated its terminal parts. Thus there seems to be a dissociation between the proximo-distal extent of regeneration of the epidermis and that of the underlying tissues. Another possible, but less likely interpretation is that the distal part of the cartilaginous core of the spike represents the terminal phalanx of a digit. In that case, one would have to postulate the formation of distal segments of a limb in the absence of intermediate segments. This is quite unlikely on the basis of both normal descriptive studies (Grim and Carlson, '74) and recent experimental work (Stocum and Dearlove, '72; Iten and Bryant, '75). The digital pad could be used as a natural marker in studies of morphogenetic mechanisms during regeneration in this species.

The general histology of both digital and arm regeneration is characterized by the rapidity and large amount of tissue healing processes, particularly of periosteal cartilage deposition and callus formation around the end of the severed bone. Noteworthy is the regular deposition of periosteal cartilage around the uninjured phalanx proximal to the amputated one (fig. 6). Neither the mechanism nor the significance of this phenomenon is understood, but it is not confined to Hyperolius alone. Nor is it known why in frogs particularly, cartilaginous callus formation occurs so rapidly and to such an extent that it damages other soft tissues of the stump (fig. 15). The degree of tissue healing is so great (a phenomenon associated with non-regenerative systems) that until a blastema is established, one would be inclined to predic: from the histology that the limb would not regenerate.

The finding of natural regeneration in Hyperolius extends the range of natural regenerative capacity in anura farther up the phylogenetic scale than was previously known. Hyperolius (in the family Hyperoliidae) is closely related to the family Ranidae (Liem, '70), one of the families of advanced frogs. The other anurans with some or abortive natural limb regen- 
erative ability are primarily in the families Discoglossidae and Pipidae, representatives of archaic frogs.

\section{ACKNOWLEDGMENTS}

The authors would like to thank $\mathrm{Mr}$. William L. Brudon for photographs of the gross specimens. Special thanks are due to Dr. Mohammed Hyder, chairman of the Zoology Department of the University of Nairobi for courtesies extended to CMR during her stay in Kenya.

\section{LITERATURE CITED}

Beetschen, J. 1952 Extension et limites du pouvoir régénérateur des membres après la metamorphose chez Xenopus laevis. Bull. Biol. de la France et de la Belgique, 86: 88-100.

Carlson, B. M. 1967 The histology of inhibition of limb regeneration in the newt, Triturus, by actinomycin D. J. Morph., 122: 249-263.

1968 Regeneration of the completely excised gastrocnemius muscle in the frog and rat from minced muscle fragments. J. Morph., 125: $447-472$.

1970 Relationship between the tissue and epimorphic regeneration of muscles. Am. Zool., 10: 175-186.

Dent, J. 1962 Limb regeneration in larval and metamorphosing individuals of the South African clawed toad. J. Morph., 110: 61-78.

Ernst, V. V. 1973a The digital pads of the tree frog, Hyla cinerea. I. The epidermis. Tissue and Cell, 5: 83-96.

$1973 \mathrm{~b}$ The digital pads of the tree frog, Hyla cinerea. II. The mucous glands. Tissue and Cell, 5: 97-104.

Forsyth, J. 1946 The histology of anuran limb regeneration. J. Morph., 79: 287-332.

Goode, R. P. 1962 Regeneration of limbs in adult Hymenochirus boettgeri. Nature (London), 193: 1098.

1967 Regeneration of limbs in adult anurans. J. Emb. Exp. Morph., 18: 259-267.

Grim, M., and B. M. Carlson 1974 A comparison of morphogenesis of the forearm and hand during ontogenesis and regeneration in the axolotl (Ambystoma mexicanum). II. The development of muscular pattern in the embryonic and regenerating limb. Z. Anatomie, 145: 149-167.

Hay, E. D. 1968 Dedifferentiation and metaplasia in vertebrate and invertebrate regeneration. In: The Stability of the Differentiated State. H. Ursprung, ed. Springer-Verlag, Berlin, pp. 85-108.

Iten, L. E., and S. V. Bryant 1973 Forelimb regeneration from different levels of amputation in the newt, Notophthalmus viridescens: length, rate and stages. Roux' Arch., 173: 263-282.

1975 The interaction between the blastema and stump in the establishment of the anterior-posterior and proximo-distal organization of the limb regenerate. Devel. Biol., 44: 119 147.

Komala, Z. 1957 Comparative investigations on the course of ontogenesis and regeneration of the limbs in Xenopus laevis tadpoles in various stages of development (Polish). Folia Biol., Krakow, 5: 1-51.

Liem, S, S, 1970 The morphology, systematics and evolution of the old World treefrogs (Rhacophoridae and Hyperoliidae). Fieldiana Zool., 57: 1-145.

National Research Council, Institute of Laboratory Animal Resources, Subcommittee on Amphibian Standards 1974 Amphibians: guidelines for the breeding, care and management of laboratory animals.

Noble, G. K., and M. E. Jaeckle 1928 The digital pads of the tree frogs. A study of the phylogenesis of an adaptive structure. J. Morph., 45: 259-292.

Overton, J. 1963 Patterns of limb regeneration in Xenopus laevis. J. Exp. Zool., 154: 153-161.

Polezhaev, V. 1972 Loss and Restoration of Regenerative Capacity in Tissues and Organs of Animals. Harvard Univ. Press, Cambridge.

Rose, S. M. 1944 Methods of initiating limb regeneration in adult anura. J. Exp. Zool., 95: 149-167.

Schiøtz, A. 1967 The Treefrogs (Rhacophoridae) of West Africa. Spolia Zool. Mus. Laun., 25: $1-346$.

1971 The superspecies Hyperolius viridiflavus (Anura). Vidensk. meddel. Dansk Naturhist. Forening, 134: 21-76.

1975 The Treefrogs of Eastern Africa, (in press).

Schotté, O., and M. Harland 1943 Amputation level and regeneration in limbs of late Rana clamitans tadpoles. J. Morph., 73: 329-361.

Schuberg, A. 1895 Über den Bau und die Funktion der Haftapparate des Laubfrosches. Arb. Zool. Zootom., Inst. Würzburg, 10: 57-118.

Singer, M., K. Rzehak and C. S. Maier 1967 The relation between the caliber of the axon and the trophic activity of nerves in limb regeneration. J. Exp. Zool., 166: 89-98.

Skowron, S., and Z. Komala 1957 Regeneration in post-metamorphic Xenopus laevis. Folia Biol., 5: 53-72

Stocum, D. L., and G. E. Dearlove 1972 Epidermal-mesodermal interaction during morphogenesis of the limb regeneration blastema in larval salamanders. J. Exp. Zool., 181: 49-62.

Thornton, C. S. 1938 The histogenesis of muscle in the regenerating forelimb of larval Ambystoma punctatum. J. Morph., 62: 17-47.

1956 Epidermal modifications in regenerating and in non-regenerating limbs of anuran larvae. J. Exp. Zool., 131: 373-393.

Weis, J. 1972 The effects of nerve growth factor on bullfrog tadpoles (Rana catesbeiana) after limb amputation. J. Exp. Zool., 180: 385-392.

Welsch, U., V. Storch and W. Fuchs 1974 The fine structure of the digital pads of rhacophorid tree frogs. Cell Tissue Res., 148: 407-416. 


\section{PLATES}


PLATE 1

EXPLANATION OF FIGURES

4 Three day digital regenerate. The amputation surface has been sealed off by a wound epidermis (E). A typical early inflammatory reaction is occurring in the underlying tissues (arrows) $\mathrm{H}+\mathrm{E} . \times 71.5$.

5 Five day digital regenerate. The apical wound epithelium is beginning to thicken. The dedifferentiative reaction has removed most of the mature muscle from the distal digital segment. The differentiation of periosteal cartilage has not yet begun. $\mathrm{H}+\mathrm{E} . \times 71.5$.

6 Seven day digital regenerate. Beneath the thickened apical epidermis (E) osteoclastic destruction of bone has occurred, and the dedifferentiative reaction is pronounced. Deposition of periosteal cartilage (arrow) has begun around the proximal phalanx. It can be readily distinguished from the cartilage $(C)$ derived from the epiphysis. $H+E$. $\times 71.5$.

7 Differentiating cone blastema in 14 day regenerate. The basal layer of cells in the wound epidermis arranged in columnar fashion. A central rod of cartilage (C) is beginning to differentiate within the blastema and a thick cuff of periosteai cartilage (PC) has already been laid down. $\mathrm{H}+\mathrm{E} . \times 66$.

8 Fifteen day digital regenerate. The ventral epidermis (E) is beginning to thicken into the layers characteristic of the digital pad. Early rudiments of the mucous glands (arrows) are also appearing. $\mathrm{H}+\mathrm{E} . \times 66$. 

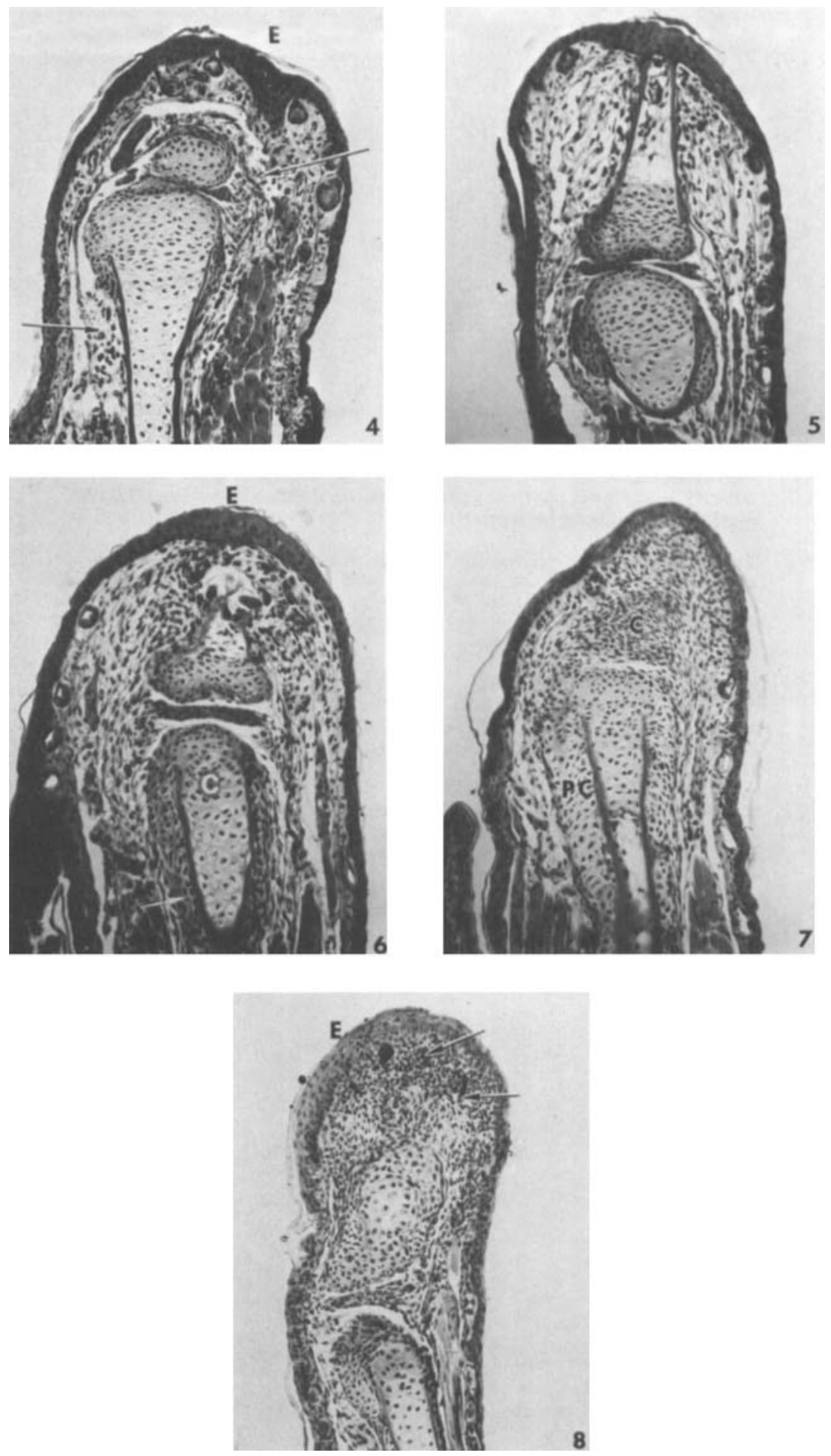
PLATE 2

\section{EXPLANATION OF FIGURES}

9 Eighteen day digital regenerate. High power view of early stages in the differentiation of mucous glands (M) of the digital pad. Mitotic activity is intense. Distinct layering of the epithelial portion (E) of the digital pad can now be seen. $\mathrm{H}+\mathrm{E} . \times 165$.

10 Twenty one day regenerate. Frontal section. Differentiation of the epithelial portion (E) of the digital pad is virtually complete. Large numbers of mucous glands (M) are seen in the soft tissues. Their overall morphology is mature, but the cytoplasm of the acini is still not fully differentiated. $\mathrm{H}+\mathrm{E} . \times 66$.

11 Twenty five day digital regenerate. Frontal section. The state of differentiation of the digital pad and underlying mucous glands is very similar to that of figure 10. Remnants of the original transected phalanx (P) are embedded within a newly regenerated mass of cartilage (C). H + E. $\times 60.5$.

12 Thirty day digital regenerate. Sagittal section. Except for the structure and shape of the regenerated skeletal elements, the regenerate is difficult to distinguish from a normal digit. Arrows indicate the level of amputation. $\mathrm{H}+\mathrm{E} . \times 22$.

13 Sagittal section through the tip of a normal digit, illustrating structures characteristic of the digital pad. E, thickened ventral epidermis; $\mathrm{N}$, neck of mucous gland; $S$, secretory portion of mucous gland; $C$, bundle of collagen fibers. $\mathrm{H}+\mathrm{E} . \times 22$. 

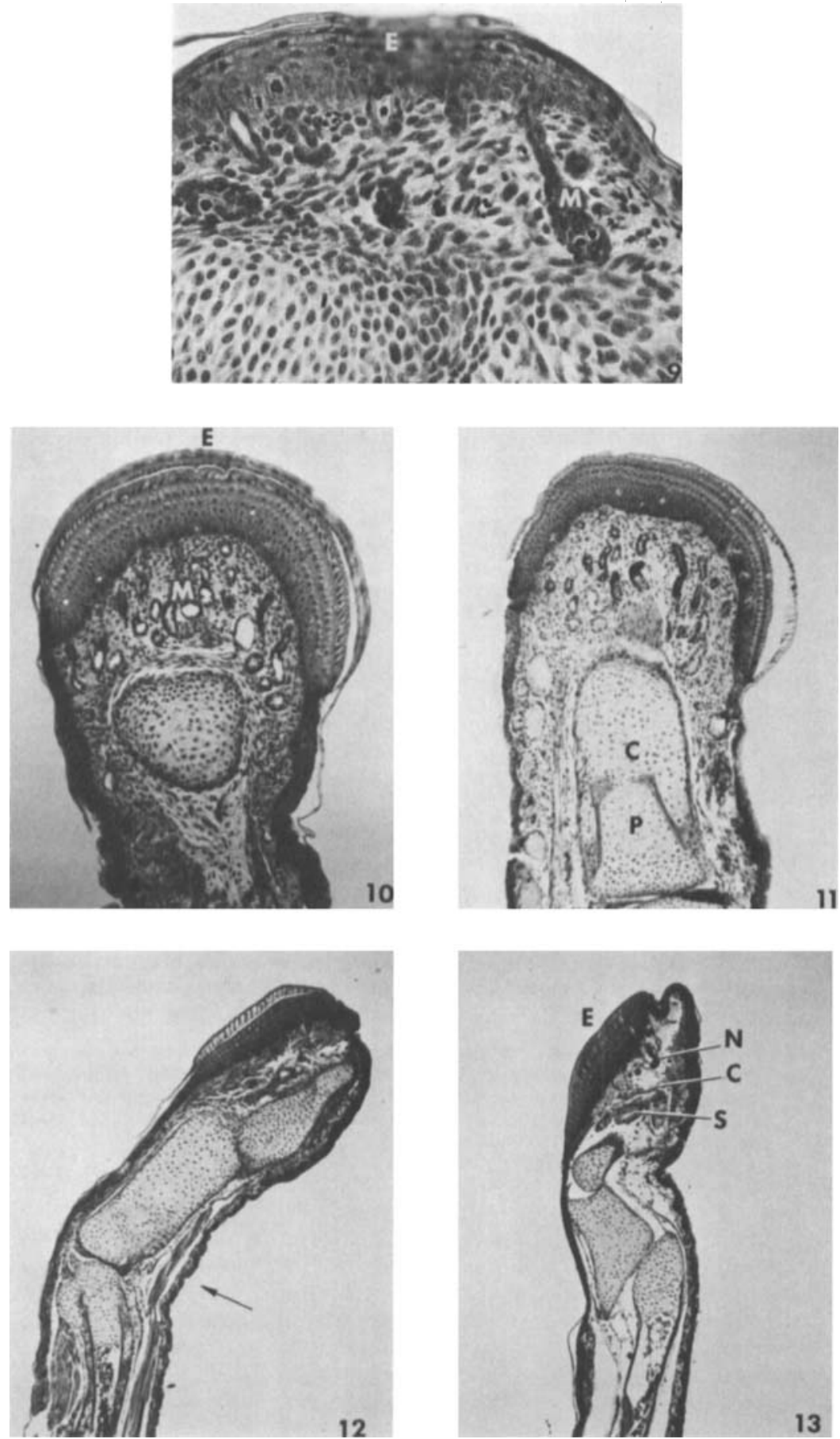


\section{PLATE 3}

\section{EXPLANATION OF FIGURES}

14 Nine day forearm regenerate. There is ample direct contact between the thickened wound epidermis (E) and dedifferentiating mesodermal tissues beneath. The arrow marks the area where bone has been re moved by osteoclastic activity. Surrounding the bone is a massive cuff of newly deposited periosteal cartilage (C). L, lymph space. $\mathbf{H}+\mathbf{E}$ $\times 19.25$.

15 High power view of regenerate shown in figure 14. The periosteal cartilaginous cuff expanded so rapidly that it engulfed normal muscle fibers, causing the degeneration (D) of the imprisoned segments of the muscle fibers. The arrow shows a junction between the proximal (normal) position of a muscle fiber and the distal degenerated segment. $\mathrm{H}+\mathrm{E} . \times 151.25$.

16 Thirteen day forearm regenerate. Regeneration has progressed to the mid cone stage. Large numbers of blastemal cells have accumulated beneath the wound epidermis. Arrows show the level of amputation. $\mathrm{H}+\mathrm{E} . \times 60.5$.

17 Fifty day forearm regenerate. This is a typical spike regenerate with a prominent jointed central rod of cartilage and sparse muscle fibers running alongside. Digital pad structures have not yet formed at the end of this spike. $\mathrm{H}+\mathrm{E} . \times 15.4$.

18 Seventy day forearm regenerate. Sagittal section. This regenerate was hypomorphic and did not possess digits. Nevertheless a readily recognizable digital pad had formed. E, multilayered epidermal component of the digital pad. Portions of sparse mucous glands are not readily seen in this section. All tissue in this figure is regenerated. $\mathbf{H}+\mathbf{E}$. $\times 60.5$.

19 Eighty day forearm regenerate. This hypomorphic regenerate was structurally more complex than that shown in figure 18. Individual cartilaginous (C) structures (carpal elements?) but no digits are present. This section shows abundant terminal mucous glands (M). All tissue in this figure is regenerated. H E. $\times 29.15$. 

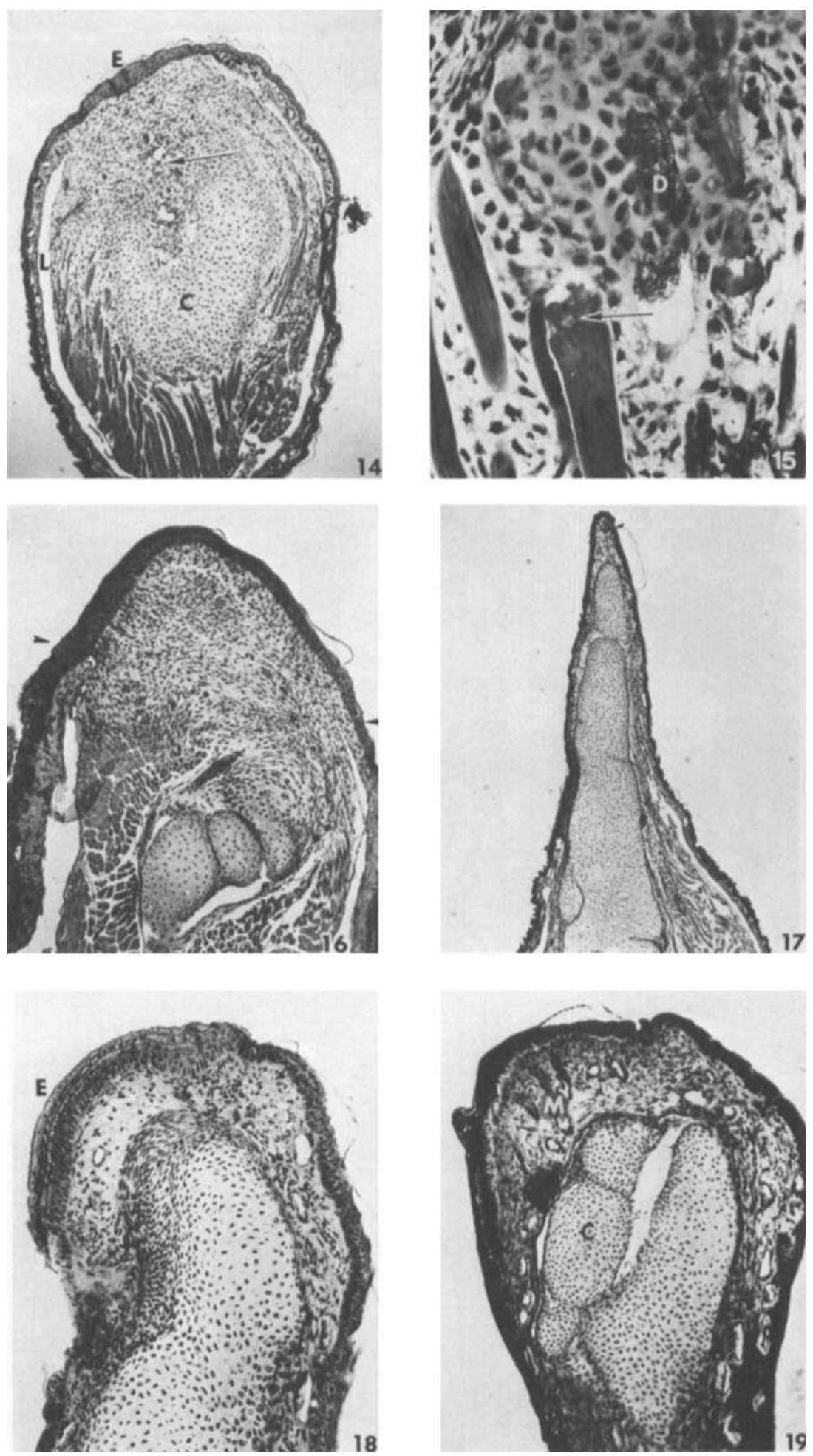